TITLE:

\title{
Water-processed self-assembles of monolayers as interface modifier for ZnO/P3HT hybrid solar cells
}

\author{
$\operatorname{AUTHOR}(\mathrm{S})$ : \\ Ruankham, Pipat; Yoshikawa, Susumu; Sagawa, \\ Takashi
}

\section{CITATION:}

Ruankham, Pipat ... [et al]. Water-processed self-assembles of monolayers as interface modifier for ZnO/P3HT hybrid solar cells. Materials Chemistry and Physics 2013, 141(1): 278-282

ISSUE DATE:

2013-08

URL:

http://hdl.handle.net/2433/177061

\section{RIGHT:}

(c) 2013 Elsevier B.V.; この論文は出版社版でありません。引用の際には 出版社版をご確認ご利用ください。; This is not the published version. Please cite only the published version. 


\section{*Highlights (for review)}

\section{Highlights}

- Hybrid solar cells using P3HT as donor and $\mathrm{ZnO}$ nanorods as acceptor were fabricated

- Benzoic acid based molecules were used for surface modification of $\mathrm{ZnO}$ as SAMs

- Linear relationship between dipole moment of SAMs and $V_{\text {oc }}$ of devices was found

- Aggregation of the molecules was found in aqueous solution

- Ordered orientation of SAMs have better charge collecting properties 


\title{
*Manuscript
}

Click here to view linked References

4

5

\section{Water-processed Self-assembles of Monolayers as Interface Modifier for ZnO/P3HT Hybrid Solar Cells}

\author{
Pipat Ruankham, ${ }^{1}$ Susumu Yoshikawa ${ }^{2}$ and Takashi Sagawa ${ }^{1 *}$ \\ 'Graduate School of Energy Science, Kyoto University, Yoshida-Honmachi, Sakyo-Ku, \\ Kyoto 606-8501, Japan \\ ${ }^{2}$ Institute of Advanced Energy, Kyoto University, Gokasho, Uji, Kyoto, 611-0011, Japan
}

E-mail address: patto@iae.kyoto-u.ac.jp (P. Ruankham), s-yoshi@iae.kyoto-u.ac.jp (S.Yoshikawa) , sagawa.takashi.6n@kyoto-u.ac.jp (T.Sagawa)

Corresponding author at: Graduate School of Energy Science, Kyoto University, Yoshida-Honmachi, Sakyo-Ku, Kyoto 606-8501, Japan Tel: +81-75-753-5624. Fax: +81-75-753-5627.

E-mail address: sagawa.takashi.6n@kyoto-u.ac.jp (T.Sagawa) 


\section{Abstract}

Benzoic acid based molecules were used for surface modification of $\mathrm{ZnO}$ nanorods as self-assembled monolayers (SAMs) in order to improve the interface interaction between $\mathrm{ZnO}$ and poly(3hexylthiophene) in hybrid solar cells. The dipole moment of the molecules and the solvent used for the surface modification were investigated in relation to the performance of the hybrid devices. A linear relationship between the dipole moment of the interface modifiers and the open circuit voltage $\left(V_{\mathrm{oc}}\right)$ of the devices were found. The $V_{\mathrm{oc}}$ are enhanced by the use of the molecules with their dipole moment pointing away from the $\mathrm{ZnO}$ surface and vice versa. The enhancement in $V_{\mathrm{oc}}$ is attributed to the shift of the vacuum level of $\mathrm{ZnO}$ when the surface is modified by the SAMs. When water was used as the solvent for surface modification process, aggregate was found in the solution state. This implies an ordered orientation of SAMs attached onto the $\mathrm{ZnO}$ surface, resulting in the improvement of the $V_{\text {oc }}$. An enhancement in the incident photon to current efficiency spectra was also obtained in the devices prepared from aqueous solution. The SAMs prepared from aqueous solution have better charge collecting properties in comparison to that prepared from ethanol solution.

\section{Keywords}

Interface modification, $\mathrm{ZnO}$ nanorod, $\mathrm{SAM}$, solvent, hybrid solar cell 


\section{Introduction}

In recent years, hybrid inorganic/polymer photovoltaic devices (HPVs) have been broadly studied because of their fundamental research interest and application potential. The concept of HPVs is a combination of organic materials (p-type polymers) and inorganic ones (n-type nanostructured metal oxides) $[1,2]$. Many inorganic materials such as $\mathrm{TiO}_{2}[3], \mathrm{ZnO}[2,4], \mathrm{Si}[5,6]$ and so on, have been selected as an electron acceptor in HPVs. Among these inorganic materials, vertically-aligned $\mathrm{ZnO}$ nanorods show good potential for an application in HPVs and other electronic devices because of their low temperature processability $[7,8]$ and high carrier mobilities with a direct electron pathway to the electrode $[9,10]$.

However, when an HPV is fabricated by pairing the most widely used p-type donor, poly(3hexylthiophene) (P3HT) with the $\mathrm{ZnO}$ nanorods, measured power conversion efficiencies (PCEs) are quite low in comparison to conventional organic photovoltaic devices (OPVs) [11, 12]. In our previous report [2], we reported an approach to improve the photovoltaic performance of HPV by surface modification with organic dye molecules with different functional group and absorption range. It was found clearly that the improvement in short circuit current density $\left(J_{\mathrm{sc}}\right)$ corresponds to the extension of the absorption range of the devices when squaraine dyes, which absorb light in the near infrared region, are used. Moreover, open circuit voltage $\left(V_{o c}\right)$ of the devices shows a relationship with the dipole moment $(\mu)$ of the interface modifier. The enhanced $V_{\text {oc }}$ can be achieved by attaching the dye molecules with their $\mu$ pointing away from the $\mathrm{TiO}_{2}$ surface $[13,14]$, and the same effect could be expected for $\mathrm{ZnO}$.

However, the selected dyes have different functional group and molecular size, which may affect the $V_{\mathrm{oc}}$ and fill factor $(F F)$ of the devices [15]. In this work, self-assemble monolayers (SAMs) are used as the interface modifier for the $\mathrm{ZnO}$ nanorods since their dipole moment can change the surface potential of the adsorbing surface $[16,17]$. Benzoic acid based molecules with different para groups 
are selecte.d because they provide a range of different magnitudes and direction of the $\mu$. Moreover, the effects of the solvent for SAMs modification are investigated to study the adsorption mechanism on $\mathrm{ZnO}$ and the relationship to the photovoltaic performances.

\section{Experimental section}

The $\mathrm{ZnO}$ nanorods were synthesized by the method described in previously reported procedures [2]. Dense $\mathrm{ZnO}$ layers, serving as seed for the $\mathrm{ZnO}$ nanorods, were prepared by spin coating a 1:1 molar mixture of $\mathrm{Zn}$ acetate and monoethanolamine in 2-methoxyethanol on ITO substrates. After that, the substrates were annealed on a hot plate at $300^{\circ} \mathrm{C}$ for $10 \mathrm{~min}$. The hydrothermal growth of $\mathrm{ZnO}$ nanorod arrays was carried out by suspending the seed substrates in an aqueous solution of zinc nitrate hexahydrate and hexamethylenetetramine at $90^{\circ} \mathrm{C}$. The resulting length of the nanorods is approximately $240 \mathrm{~nm}$. Then, the substrates were carefully rinsed with distilled water and annealed at $150^{\circ} \mathrm{C}$ for $10 \mathrm{~min}$.

Surface modification with benzoic acid based SAMs was performed by immersing the $\mathrm{ZnO}$ nanorods substrates in solutions $(30 \mu \mathrm{M})$ of benzoic acid (BA), 4-aminobenzoic acid (ABA), 4(diethylamino)benzoic acid (DBA), 4-nitrobenzoic acid (NBA), and 4-cyanobenzoic acid (CBA) in ethanol or deionized water at room temperature for $1 \mathrm{~h}$. The substrates were carefully rinsed with ethanol or deionized water after the deposition of SAMs.

A solution of P3HT in chlorobenzene $\left(30 \mathrm{mg} \mathrm{ml}^{-1}\right)$ was spin-coated on top of the SAMsmodified $\mathrm{ZnO}$ nanorods and subsequently annealed at $150^{\circ} \mathrm{C}$ for $3 \mathrm{~min}$ in a $\mathrm{N}_{2}$ filled glove box. Finally, the $\mathrm{MoO}_{\mathrm{x}}(15 \mathrm{~nm})$ and $\mathrm{Ag}$ top electrode $(100 \mathrm{~nm})$ was thermally deposited in a vacuum evaporation system. The basic schematic structure of the devices is shown in Figure 1.

The dipole moment calculation was performed by using single-point electronic structure with semi-empirical MOPAC program with PM3 model in HyperChem package. UV-vis absorption 
measurement was carried out using a UV-Vis spectrophotometer (UV-2450 Shimadazu). The photocurrent-voltage characteristics were characterized under ambient atmosphere and simulated solar light, $\mathrm{AM} \mathrm{1.5,100} \mathrm{mW} \mathrm{cm}{ }^{-2}$ (CEP-2000 Bunkoh-Keiki). The light intensity was calibrated by using a standard silicon photodiode (BS520, Bunkoh-Keiki).

\section{Results and discussion}

The morphologies of the $\mathrm{ZnO}$ nanorods prepared by hydrothermal growth are shown in Figure 2a. The diameter and length are about $25 \mathrm{~nm}$ and $240 \mathrm{~nm}$, respectively. The P3HT is able to infiltrate into rod-to-rod space as confirmed by the cross-sectional FE-SEM images in Figure 2b. For the device with surface modification, there is no expected change in the morphologies of $\mathrm{ZnO}$ nanorods after immersing the as-prepared $\mathrm{ZnO}$ nanorod substrates into the ethanol and aqueous solutions, since the concentration of the solution is low $(30 \mu \mathrm{M})$, yielding $\mathrm{pH}$ values of about 7 . Also, the $\mathrm{p} K_{\mathrm{a}}$ values of the SAMs are in the range of 3.4-4.6, which indicate that the solutions of SAMs are weak acid.

In order to find the effect of dipole moment on the photovoltaic performance, the $\mu$ of the benzoic acid based molecules were calculated using semi-empirical models from the HyperChem software. The orientations of the molecules used for calculating $\mu$ are in such a way that the $C 2$ axis of the carboxylate is parallel to the $Z$-axis, while the $\mathrm{ZnO}$ surface plane is parallel to the $x$ - and $y$-axes. This is because interface molecules generally attach to metal oxide or metal surfaces by their carboxylic or carboxylate group [18, 19]. After the adsorption of SAMs on the ZnO surface, the magnitude of dipole moment may change since the carboxylic group lessens in its electronwithdrawing property. However this change is not significant [14]. The evaluated magnitudes and directions of $\mu$ are shown in Table 1 and Figure $3 \mathrm{a}$. It can be seen that the $\mu$ of BA, ABA, and DBA points away from the $\mathrm{ZnO}$ surface while one of $\mathrm{CBA}$ and NBA points toward the $\mathrm{ZnO}$ surface. Note that the positive value of $\mu$ indicates its direction pointing away from the $\mathrm{ZnO}$ surface. 
Figure $3 b$ and $3 c$ compares the optimized molecular structure and electron distribution of benzoic acid based molecules at highest occupied molecular orbital (HOMO) and lowest unoccupied molecular orbital (LUMO). The electron density is distributed over the benzene rings and para group of the molecules at the HOMO state, while the electron distribution over the carboxylic group of the molecules is also observed at the LUMO state. This indicates that under illumination, the photoexcited electron is directed to inject into the conduction band of the $\mathrm{ZnO}$ via carboxylic group of the molecules. This confirms that the molecules are able to act as the interface modifier of a semiconductor.

The molecules were attached onto the $\mathrm{ZnO}$ surface by using either water or ethanol as the solvent. The photovoltaic performances of the devices corresponding to the change in $\mu$ of the SAMs are plotted in Figure 4 . The relation between $J_{\mathrm{sc}}$ of the hybrid devices and the $\mu$ of the molecules is not clear as seen in Figure $4 a$. The $d_{s c}$ is rather related to the light absorption range of the modifying molecules and the tail of the modifiers facing P3HT [2]. Moreover, the use of water as solvent for SAMs is found to yield higher $d_{s c}$ than the use of ethanol. This is because SAMs prepared from an aqueous solution have higher level of ordering on the $\mathrm{ZnO}$ surface and less surface impurities than the ones prepared from ethanol solution. The role of electron transport will be explained below.

A linear relationship between the $\mu$ of the molecules and $V_{\text {oc }}$ (Figure $4 \mathrm{~b}$ ) was found. The $V_{\text {oc }}$ of the devices modified with $\mathrm{BA}, \mathrm{ABA}$, and $\mathrm{DBA}$ is relatively high in comparison to that of the device modified with NBA and CBA. This is attributed to the $\mu$ of $\mathrm{BA}, \mathrm{ABA}$, and DBA pointing away from the $\mathrm{ZnO}$ surface, resulting in the downward shift of the vacuum level of the $\mathrm{ZnO}$ semiconductor (passing from $\mathrm{ZnO}$ to $\mathrm{P} 3 \mathrm{HT}$ ) and greater band bending at the $\mathrm{ZnO} / \mathrm{P} 3 \mathrm{HT}$ interface $[13,14]$. The highest improvement in $V_{\mathrm{oc}}$ of the devices is obtained from the device modified with ABA in aqueous solution. The $V_{\mathrm{oc}}$ of the ABA device increases from $0.39 \mathrm{~V}$ for the unmodified device to $0.41 \mathrm{~V}$ and $0.46 \mathrm{~V}$ for the devices using ethanol and water as solvent, respectively. 
In Figure 4c, the plot between the $\mu$ of SAMs and the fill factor $(F F)$ of the hybrid devices also shows a linear relationship, which is similar to the trend of $\mu$ and $V_{\mathrm{oc}}$ (Figure 4b). However, the use of benzoic acid based molecules with the $\mu$ pointing away from the $\mathrm{ZnO}$ surface does not show a significant improvement in FF in comparison to the unmodified devices. This indicates that the charge recombination at the $\mathrm{ZnO} / \mathrm{P} 3 \mathrm{HT}$ interface modified with small molecules is not significantly reduced in comparison to the case of the devices modified with large molecules such as C60-SAMs [1] and dye molecules [2], which have a longer charge carrier lifetime [15].

It is seen clearly that the molecules with dipole moment pointing toward the $\mathrm{ZnO}$ surface deteriorate both $V_{o c}$ and $F F$ of the devices. However, for the molecule with dipole moment pointing away from the $\mathrm{ZnO}$ surface, the expected improvement in $V_{\mathrm{oc}}$ and $F F$ from the calculated dipole moment of the SAMs could not be achieved since the actual dipole moment of the ZnO/SAMs complex is less than the dipole moment of the SAMs. This is because of the interfacial dipole between $\mathrm{COO}^{-}$ group and $\mathrm{ZnO}$ that points toward $\mathrm{ZnO}[16]$. The highest power conversion efficiency $(P C E)$ of $0.53 \%$ is achieved from the ABA-modified device prepared from aqueous solution (Figure 4d), while one prepared from ethanol solution shows lower $P C E$ of $0.41 \%$, which is mainly due to lower $J_{\text {sc }}$ and $V_{\text {oc }}$.

In order to understand the effect of solvent and the $\mu$ of SAMs on the $V_{o c}$ of the device, reverse saturation current density $\left(J_{0}\right)$ was extracted from $J V$ curve (Figure 5 a) under the dark conditions by using the diode equation [20]; $J=J_{0}\left(e^{q V / n k_{B} T}-1\right)$ where $J_{0}$ is reverse saturation current density, $n$ is ideality factor, $q$ is the elementary charge, $k$ is Boltzmann constant and $T$ is temperature. The equation can be fitted well to the dark $J V$ curve in an exponential regime $(0.1<V<0.4)$ as shown in Figure $5 b$. The plot between the extracted $J_{0}$ and the $\mu$ of the SAMs in Figure 6 represents a linear relationship. This is attributed to the leakage-blocking behavior of the electric field generated by the $\mu$ with their direction pointing away from the surface [2]. 
The reduction of $J_{0}$ would increase the $V_{\text {oc }}$ of the device which is described by the equation $V_{\text {oc }}=$ $(n k T / q) \ln \left(J_{\mathrm{sc}} / J_{0}+1\right)[2]$.

For the effect of solvent on the photovoltaic performances, the absorbance and photoluminescence of $\mathrm{ABA}$ in ethanol and aqueous solution at various concentrations were measured and the resulting spectra are shown in Figure 7. When the concentration of the solution increases, the red shift, which was found only in the case of aqueous solution (Figure 7a), was observed. This indicates that there is an aggregate formation of the molecules in the solution state. This maybe attributed to a high polarity of water, which prefers to interact with a carboxylic group than the benzene ring of the interface modifier molecules. Since an interaction among benzene rings of the benzoic based molecules is not disturbed by the existence of water molecules, allowing the molecules to form the aggregate. While, the shift of the absorbance peak and photoluminescence peak was not found in the case of ethanol solution (Figure 7b). This is because a non-polar part of ethanol may interact with the benzene ring of the SAM molecules, blocking the aggregate formation.

When the molecules are adsorbed onto the $\mathrm{ZnO}$ surface, the interaction among the molecules may weaken due to the strong interaction between $\mathrm{ZnO}$ and their carboxylic group. On the other hand, the orientation of SAMs prepared from aqueous solution may have a higher level of ordering on the $\mathrm{ZnO}$ surface than one prepared from ethanol solution because of the aggregation in the solution state. The deprotonated molecules of ethanol $\left(\mathrm{CH}_{3} \mathrm{CH}_{2} \mathrm{O}^{-}\right)$are able to coordinate to the $\mathrm{Zn}$ atoms, forming a coordination bonding of $\mathrm{Zn}-\mathrm{OCH}_{2} \mathrm{CH}_{3}$ [21]. Coordinated $\mathrm{CH}_{3} \mathrm{CH}_{2} \mathrm{O}^{-}$disrupts the orientation of SAMs and serves as the interface impurity. Similarly, the molecules of water can also coordinate to the $\mathrm{Zn}$ atoms, forming $\mathrm{Zn}\left(\mathrm{OH}_{2}\right)_{\mathrm{n}}$, though the $\mathrm{Zn}\left(\mathrm{OH}_{2}\right)_{\mathrm{n}}$ is a native surface impurity of $\mathrm{ZnO}$ nanorods prepared from hydrothermal method $[4,22]$.

The orientation of SAMs and the presence of the surface impurity affect the charge generation and charge harvesting properties of the devices as confirmed by an incident photon to current 
efficiency (IPCE) measurement (Figure 8). In comparison to the unmodified device, the device prepared from aqueous solution shows the enhancement in IPCE spectra in both UV and visible region, which relate to the photo-generated charge carrier of $\mathrm{ZnO}$ and $\mathrm{P} 3 \mathrm{HT}$, respectively [2, 23]. However, the device prepared from ethanol solution does not show the enhancement in IPCE spectra in the visible region. This demonstrates that the SAMs-modified $\mathrm{ZnO}$ film prepared from aqueous solution has better potential to accept electrons from P3HT than one prepared from ethanol solution. One of the reasons is that electrons cannot transport through an alkane tail of the $\mathrm{Zn}-\mathrm{OCH}_{2} \mathrm{CH}_{3}$ complex.

\section{Conclusions}

In conclusion, an approach for the improvement of photovoltaic performance of hybrid solar cells based on $\mathrm{ZnO}$ nanorods and P3HT by modification of SAMs was presented. ABA-modified device prepared from aqueous solution gave the best $P C E$ of about $0.53 \%$. The improved performance of ABA-modified devices was mainly attributed to the dipole moment which points away from the $\mathrm{ZnO}$ surface, resulting in the enhancement of $V_{\mathrm{oc}}$ and the reduction of $J_{0}$. The orientation of SAMs on the $\mathrm{ZnO}$ surface, which is found in case of the use of water as solvent, shows the improvement in $V_{\mathrm{oc}}$ and $J_{\text {sc }}$ in comparison to the SAMs-modified device prepared from ethanol solution. Ethanol is not the proper solvent of SAMs because of the presence of $\mathrm{Zn}-\mathrm{OCH}_{2} \mathrm{CH}_{3}$ as the surface impurity.

\section{Acknowledgement}

Authors gratefully acknowledged the New Energy and Industrial Technology Development Organization (NEDO) of the Ministry of Economy, Trade, and Industry (METI), and Core Research of Evolutional Science \& Technology Agency (CREST) from Japan Science Technology Agency (JST) in addition to Global Centers of Excellence (GCOE) Program from the Ministry of Education, Culture, Sports, Science \& Technology (MEXT). 
Figure 1. Schematic device structure of $\mathrm{ZnO}$ nanorods/P3HT hybrid solar cell.

Figure 2. FE-SEM images: a) top view of $\mathrm{ZnO}$ nanorods and b) cross-sectional view of the $\mathrm{ZnO}$ nanorods/P3HT hybrid device.

Figure 3. a) Semi-empirical calculation of stabilized molecular structure and dipole moment (arrows) of benzoic acid based molecules and their charge distribution of the b) HOMO and c) LUMO orbitals.

Figure 4. Photovoltaic performance, a) short-circuit current density $\left(d_{\mathrm{sc}}\right)$, b) open-circuit voltage $\left(V_{\mathrm{oc}}\right)$, c) fill factor $(F F$, and d) power conversion efficiency ( $P C E$, of the $\mathrm{ZnO}$ nanorods/P3HT hybrid solar cells with different SAMs in ethanol (red square) and water (blue circle).

Figure 5. Photocurrent - voltage ( $J-V$ ) curves for the $\mathrm{ZnO}$ nanorods/P3HT hybrid devices without and with surface modification of the $\mathrm{ZnO}$ with $\mathrm{ABA}$ in ethanol, $\mathrm{ABA}$ in water, NBA in ethanol, and NBA in water under dark condition plotted on a semi-log scale in a range of a) $-1.0 \mathrm{~V}$ to $2.0 \mathrm{~V}$ and $\mathrm{b}$ ) $0 \mathrm{~V}$ to $0.5 \mathrm{~V}$. The diode equation (solid line in $\mathrm{b}$ ) is well fitted to experimental data (open symbol).

Figure 6. The extracted $d_{0}$ of the $\mathrm{ZnO}$ nanorods/P3HT hybrid solar cells with different SAMs in ethanol (red square) and water (blue circle) plotted versus the dipole moment of the SAMs.

Figure 7. Normalized absorbance (solid line) and photoluminescence spectra (dash line) of ABA solution in water (a) and ethanol (b) at various concentrations (35 $\mu \mathrm{M}-250 \mu \mathrm{M})$.

Figure 8. Comparison of IPCE spectra of the devices with unmodified (black) and SAMs-modified $\mathrm{ZnO}$ nanorods prepared fom ethanol (red) and water (blue) solution. 
[1] S.K. Hau, Y.J. Cheng, H.L. Yip, Y. Zhang, H. Ma, A.K.Y. Jen, Acs. Appl. Mater. Inter. 2 (2010) 1892-1902.

[2] P. Ruankham, L. Macaraig, T. Sagawa, H. Nakazumi, S. Yoshikawa, J. Phys. Chem. C 115 (2011) $23809-23816$

[3] Q.D. Tai, X.Z. Zhao, F. Yan, J. Mater. Chem. 20 (2010) 7366-7371.

[4] P. Ruankham, T. Sagawa, H. Sakaguchi, S. Yoshikawa, J. Mater. Chem. 21 (2011) 9710-9715.

[5] C.Y. Liu, Z.C. Holman, U.R. Kortshagen, Adv. Funct. Mater. 20 (2010) 2157-2164.

[6] S. Jeong, E.C. Garnett, S. Wang, Z. Yu, S. Fan, M.L. Brongersma, M.D. McGehee, Y. Cui, Nano Lett. 12 (2012) 2971-2976.

[7] L. Vayssieres, Adv. Mater. 15 (2003) 464-466.

[8] L.E. Greene, M. Law, D.H. Tan, M. Montano, J. Goldberger, G. Somorjai, P.D. Yang, Nano Lett. 5 (2005) $1231-1236$

[9] A.L. Briseno, T.W. Holcombe, A.I. Boukai, E.C. Garnett, S.W. Shelton, J.J.M. Frechet, P.D. Yang, Nano Lett. 10 (2010) 334-340.

[10] B.Q. Sun, E. Marx, N.C. Greenham, Nano Lett. 3 (2003) 961-963.

[11] D.C. Olson, Y.J. Lee, M.S. White, N. Kopidakis, S.E. Shaheen, D.S. Ginley, J.A. Voigt, J.W.P. Hsu, J. Phys. Chem. C 112 (2008) 9544-9547.

[12] P. Atienzar, T. Ishwara, B.N. Illy, M.P. Ryan, B.C. O'Regan, J.R. Durrant, J. Nelson, J. Phys. Chem. Lett. 1 (2010) 708-7.13.

[13] J. Krüger, U. Bach, M. Grätzel, Adv. Mater. 12 (2000) 447-451.

[14] C. Goh, S.R. Scully, M.D. McGehee, J. Appl. Phys. 101 (2007) 114503.

[15] M. Miyashita, K. Sunahara, T. Nishikawa, Y. Uemura, N. Koumura, K. Hara, A. Mori, T. Abe, E. Suzuki, S. Mori, J. Am. Chem. Soc. 130 (2008) 17874-17881.

[16] H.-L. Yip, S.K. Hau, N.S. Baek, H. Ma, A.K.Y. Jen, Adv. Mater. 20 (2008) 2376-2382. 
[17] H.-L. Yip, S.K. Hau, N.S. Baek, A.K.Y. Jen, Appl. Phys. Lett. 92 (2008) 193313-193313.

[18] K.E. Lee, M.A. Gomez, S. Elouatik, G.P. Demopoulos, Langmuir, 26 (2010) 9575-9583.

[19] Y. Liang, B. Peng, J. Chen, J. Phys. Chem. 114 (2010) 10992-10998.

[20] G.A.H. Wetzelaer, M. Kuik, M. Lenes, P.W.M. Blom, Appl. Phys. Lett. 99 (2011).

[21] G. Kwak, K. Yong, J. Phys. Chem. 112 (2008) 3036-3041.

[22] Q. Ahsanulhaq, A. Umar, Y.B. Hahn, Nanotechnology 18 (2007) -.

[23] D.C. Olson, Y.J. Lee, M.S. White, N. Kopidakis, S.E. Shaheen, D.S. Ginley, J.A. Voigt, J.W.P. Hsu, J. Phys. Chem. C 111 (2007) 16640-16645. 
Table 1. Dipole moment of benzoic acid based molecules.

\begin{tabular}{llccr}
\hline SAMs & \multicolumn{1}{c}{$\mu_{\mathrm{x}}$} & $\mu_{\mathrm{y}}$ & $\mu_{\mathrm{z}}$ & $|\mu|_{\text {total }}$ \\
\hline BA & 0 & 1.19 & 1.91 & 2.23 \\
ABA & 0 & 2.97 & 3.10 & 4.29 \\
DBA & 0.22 & 1.22 & 4.51 & 4.68 \\
NBA & 0 & 0.74 & -3.62 & -3.69 \\
CBA & 0 & 0.18 & -2.05 & -2.05 \\
\hline
\end{tabular}




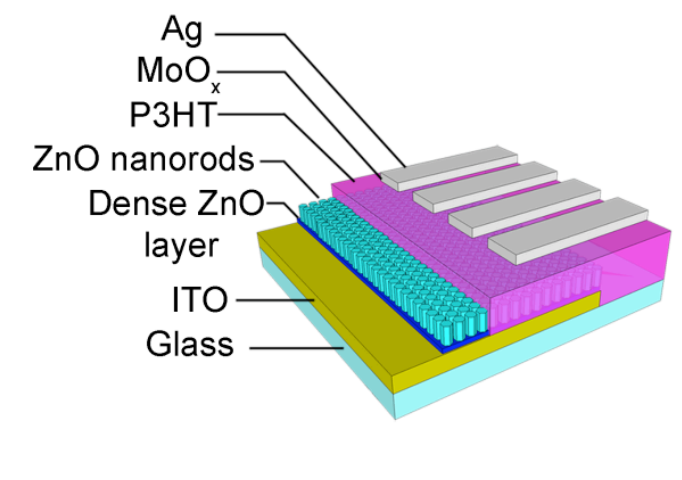

Fig 1

$\mathrm{MoO}$

nanorods-

layer

Glass

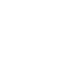

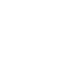

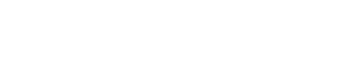

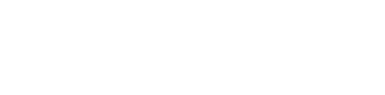



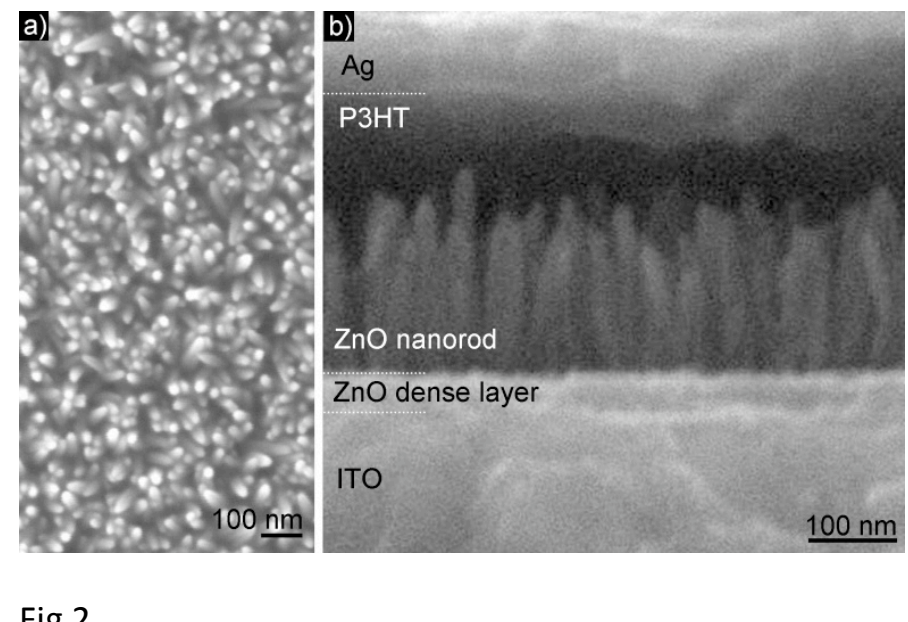

P3HT

TO

\section{(1)

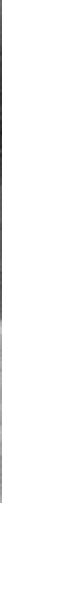

\section{Fig 2 \\ (}

(2)

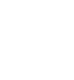

(n)
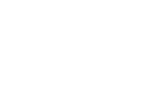

.

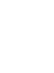

- 
Benzoic acid 4-Aminobenzoic acid 4-(Diethylamono) 4-Nitrobenzoic acid 4-Cyanobenzoic acid

(BA)

a)

b)<smiles>CCC1C(C)C(C)C(C(C)OC)C(C)C1C</smiles>

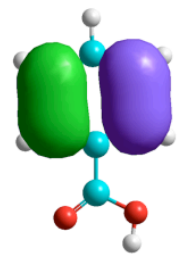

c)

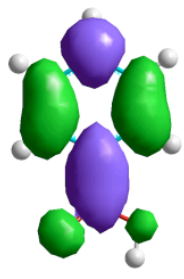

$(\mathrm{ABA})$
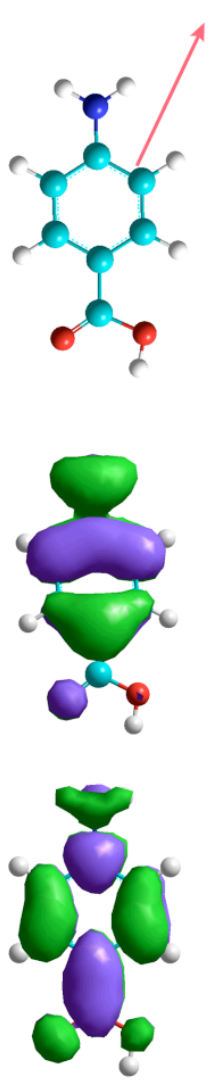
benzoic acid (DBA)

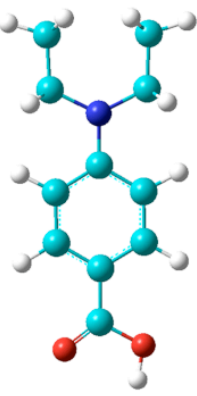

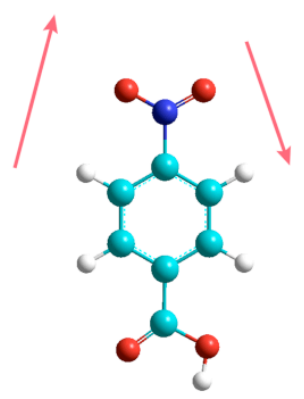
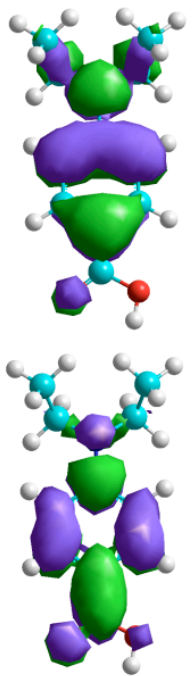

(NBA)

(CBA)
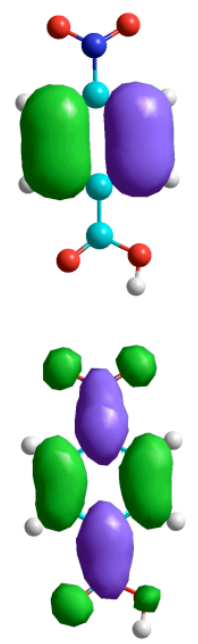<smiles>COCC1C(C)C(C)C(C)C(C)C1C(=O)OC</smiles>
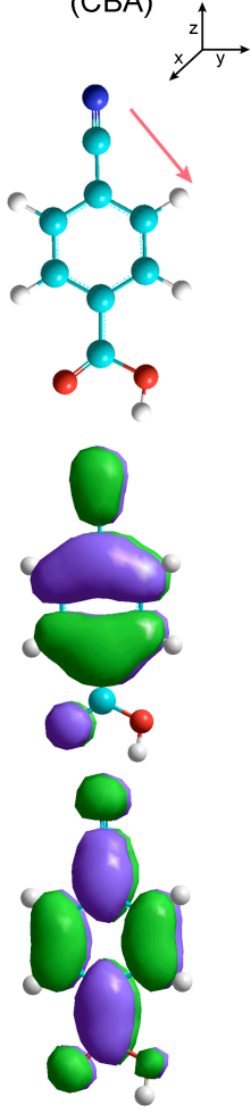

Fig 3 
a)

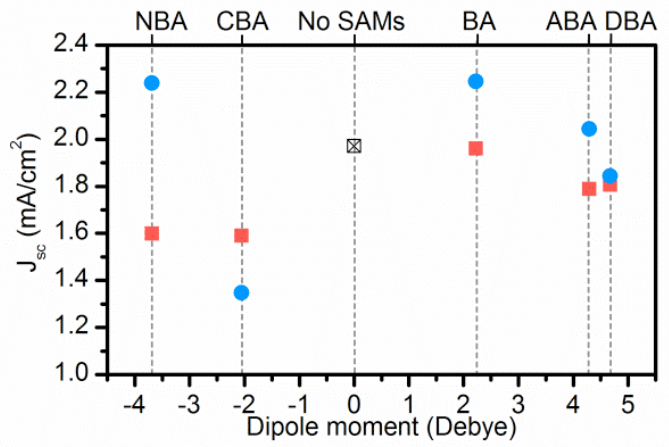

b)

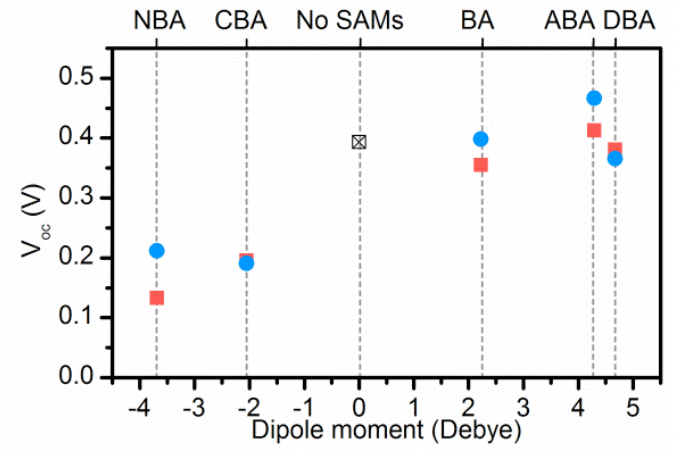

c)

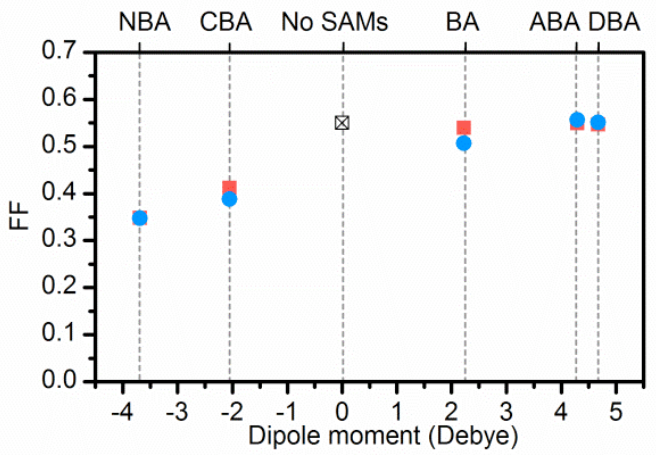

d)

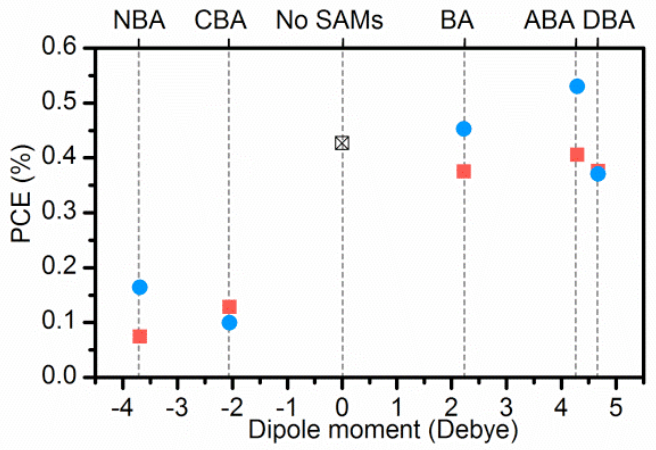

Fig 4 

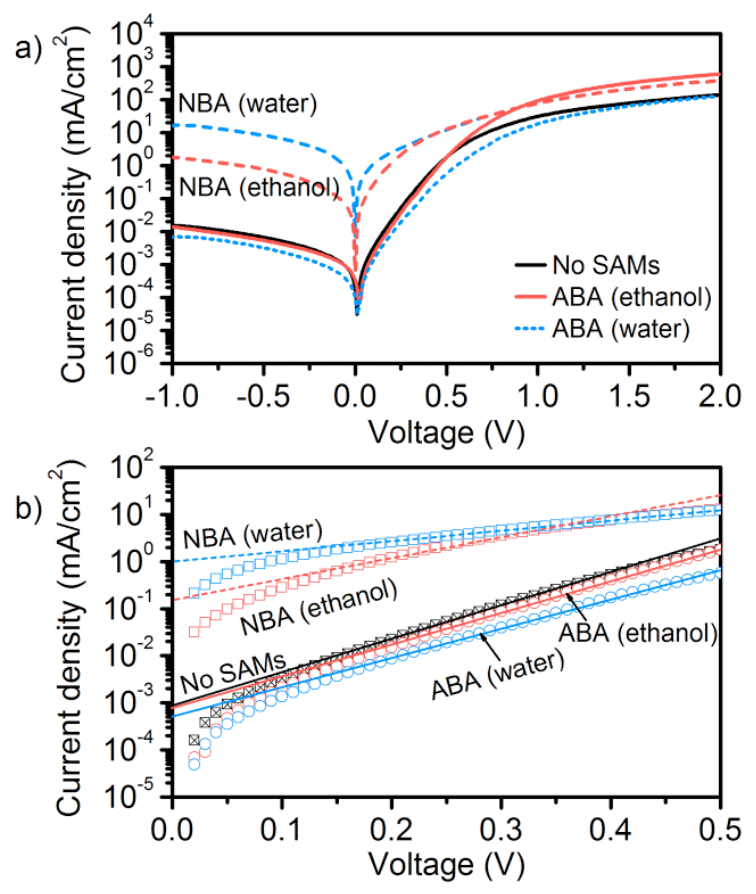

Fig 5 


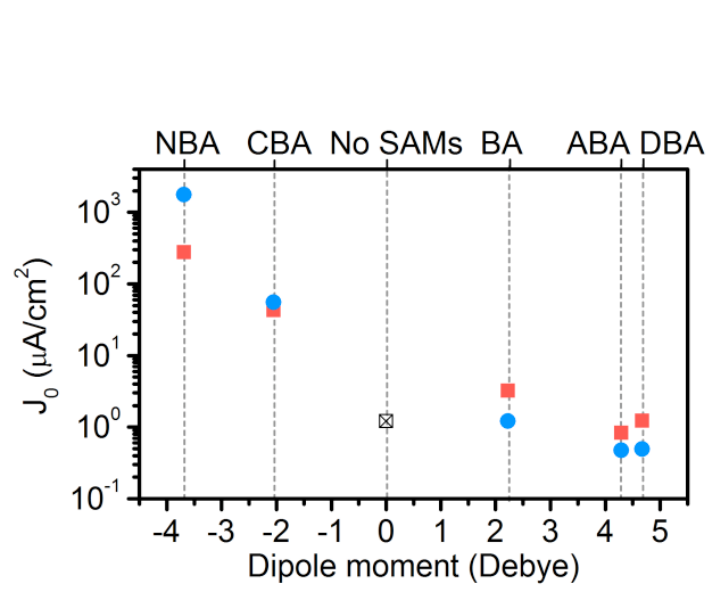

Fig 6

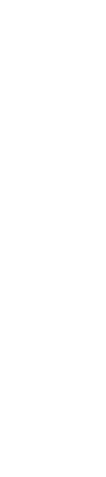


a)

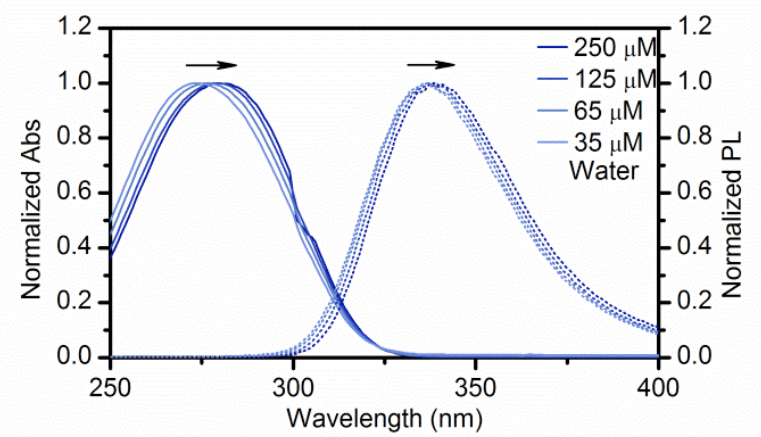

b)

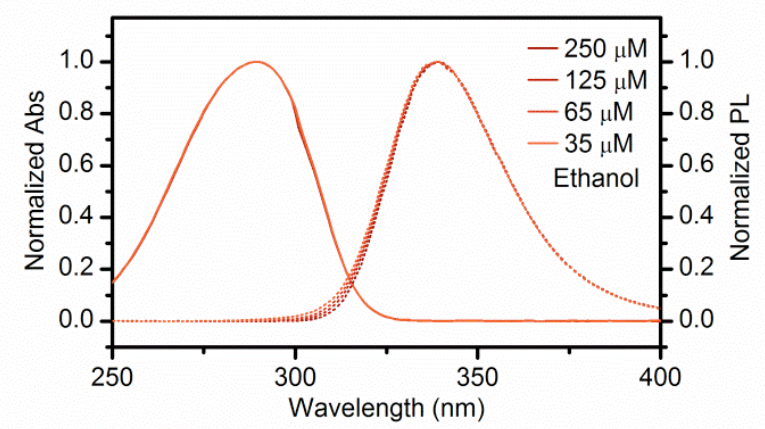

Fig 7 


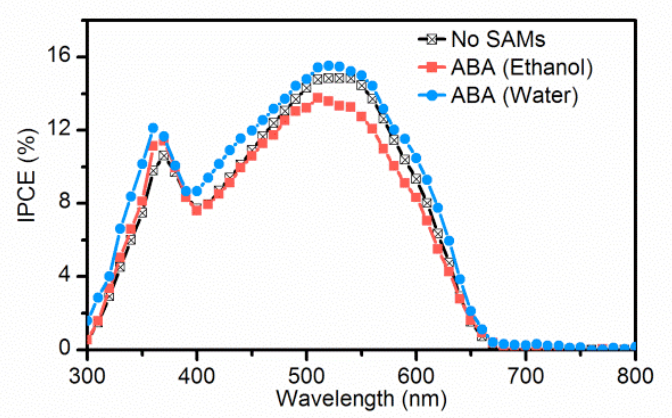

Fig 8

ig 8 